\title{
Factors Influencing Oncologic Outcomes after Tumor-specific Mesorectal Excision for Rectal Cancer
}

\author{
Kil Yeon Lee
}

Department of Surgery, Kyung Hee University Medical Center, Seoul, Korea

\section{See Article on Page 100-107}

Total mesorectal excision (TME) was proposed by Heald et al. [1] more than 20 years ago and it is defined as the complete excision of the visceral mesorectal tissue to the level of the levators. The local recurrence rate after rectal cancer surgery has decreased dramatically to below $10 \%$ thanks to this TME technique. Currently TME is the gold standard for treatment of rectal cancer. However, if the tumor is located in upper rectum, partial mesorectal excision (PME) down to $5 \mathrm{~cm}$ below tumor can be performed. In 1998, Lopez-Kostner et al. [2] from Cleveland clinic insisted that TME is not necessary in case of the upper rectal cancer. And in the same year, Zaheer et al. [3] from Mayo clinic stated that appropriate "tumor-specific" mesorectal excision during anterior resection when tumor is high in the rectum is likewise consistent with a low rate of local recurrence and good long-term survival. The term tumor-specific mesorectal excision (TSME) was noted first in this article. In the Europe, Maurer et al. [4] from Germany concluded that the rectal cancers of upper third are appropriately treated by PME to $5 \mathrm{~cm}$ below the tumor. TSME is defined as the precise perpendicular and circumferential excision of the mesorectum to the level of an appropriate distal resection margin by American Society of Colon and Rectal Surgeons.

Law and Chu et al. [5] from Queen Mary's Hospital in Hong Kong compared the patients with TME for mid and lower rectal cancer and PME for upper rectal cancer, where the rectum was transected 4 to $5 \mathrm{~cm}$ below the tumor. Due to longer operative times, higher anastomotic leak rates, a more technically demanding surgery and a higher incidence of stoma formation, the au-

Correspondence to: Kil Yeon Lee, M.D.

Department of Surgery, Kyung Hee University Medical Center,

23 Kyungheedae-ro, Dongdaemun-gu, Seoul 130-872, Korea

Tel: +82-2-958-8261, Fax: +82-2-966-9366

E-mail: isaac34@korea.com

(C) 2012 The Korean Society of Coloproctology

This is an open-access article distributed under the terms of the Creative Commons Attribution NonCommercial License (http://creativecommons.org/licenses/by-nc/3.0) which permits unrestricted noncommercial use, distribution, and reproduction in any medium, provided the original work is properly cited. thors called for a more selective use of TME. The authors argue that oncologic outcome is not compromised with this approach based on similar cancer-specific survival patterns between TME and PME in this study. This conclusion was confirmed by metaanalysis. Mirnezami et al. [6] examined the long-term oncological impact of anastomotic leakage after rectal cancer surgery using meta-analysis methods. They found that anastomotic leakage has a negative impact on local recurrence after the rectal cancer surgery. A significant association between anastomotic leakage and reduced long-term cancer specific survival was also noted. Junginger and Hermanek [7] reviewed the literature concerning oncologic outcomes after the rectal surgery. The authors recommended PME, if the rectal cancer is located 12 to $16 \mathrm{~cm}$ from anal verge.

Oncologic outcomes after the rectal cancer surgery can be divided into the long-term survival and the local recurrence rate. Regarding rectal cancer, local recurrence rate is especially important compared to colon cancer. TSME itself and its quality is one of the most important factors to predict the local recurrence and even the long-term survival after rectal cancer surgery. Survival is mainly determined by the occurrence of distant metastasis, but TME seems to improve survival in patients without systemic disease. Therefore, the effort to improve the quality of TME is so crucial to improve oncologic outcomes after rectal cancer surgery. Preoperative concurrent chemoradiotherapy is another important factor to reduce the local failure. Pathologic results, such as distal margin, circumferential radial margin, $\mathrm{T}$ and $\mathrm{N}$ stage, lymphatic and vascular invasion, neural invasion, are also important factors to influence the oncologic results after TSME.

In conclusion, surgeon is one of the most important factors to predicting oncologic outcomes after TME. Individual surgeon should make an effort to improve surgical skill and pathologist can help him with the specimen audit. Nationwide audit program is needed to improve the oncologic results after TME in rectal cancer in South Korea. The other important factor is the preoperative radiotherapy. Preoperative radiotherapy with high quality TME can almost abolish the possibility of local recurrence. 


\section{REFERENCES}

1. Heald RJ, Husband EM, Ryall RD. The mesorectum in rectal cancer surgery: the clue to pelvic recurrence? Br J Surg 1982;69:613-6.

2. Lopez-Kostner F, Lavery IC, Hool GR, Rybicki LA, Fazio VW. Total mesorectal excision is not necessary for cancers of the upper rectum. Surgery 1998;124:612-7.

3. Zaheer S, Pemberton JH, Farouk R, Dozois RR, Wolff BG, Ilstrup D. Surgical treatment of adenocarcinoma of the rectum. Ann Surg 1998;227:800-11.

4. Maurer CA, Renzulli P, Meyer JD, Büchler MW. Rectal carcino- ma. Optimizing therapy by partial or total mesorectum removal. Zentralbl Chir 1999;124:428-35.

5. Law WL, Chu KW. Anterior resection for rectal cancer with mesorectal excision: a prospective evaluation of 622 patients. Ann Surg 2004;240:260-8.

6. Mirnezami A, Mirnezami R, Chandrakumaran K, Sasapu K, Sagar P, Finan P. Increased local recurrence and reduced survival from colorectal cancer following anastomotic leak: systematic review and meta-analysis. Ann Surg 2011;253:890-9.

7. Junginger T, Hermanek P. Problems in the treatment of upper rectal carcinoma. Chirurg 2008;79:327-39. 